\title{
Effect of early programmes of high and low intensity exercise on physical performance after transmural acute myocardial infarction
}

\author{
A J Goble, D L Hare, P S Macdonald, R G Oliver, M A Reid, M C Worcester
}

\begin{abstract}
Does a programme of light exercise training after acute myocardial infarction produce the same improvement in treadmill performance as aerobic exercise training? Three hundred and eight men from a consecutive series of 479 men with transmural ( $Q$ wave) acute myocardial infarction, admitted to a single coronary care unit, were randomly allocated to eight weeks of group aerobic exercise training or group light exercise. Groups were well matched for all characteristics other than site of infarction, which did not significantly affect results. Mean (SD) physical working capacity (metabolic equivalents) determined by treadmill testing at the start of the study (in the third week after infarction) was $6.8(2.2) v 6.7(2.5)$ METs, at the end (in the eleventh week after infarction) $10.8(2.3) v 9.9(2.4)$ METs, and at 12 month review $10.8(2.4) v 10.7$ (1.9) METs for the exercise training group and the light exercise group respectively. The difference of $0.9 \mathrm{MET}$ at the end of the study was the only significant difference between groups. There were no significant intergroup differences at any stage in resting and maximal heart rate, resting and maximal systolic blood pressure, or rate-pressure product.

Apart from a small temporarily greater physical working capacity, the physical benefits of aerobic exercise training were equally well achieved by group light exercise.
\end{abstract}

Exercise training has many claimed benefits in the rehabilitation of patients after acute myocardial infarction. Physical performance was improved significantly by such programmes. ${ }^{1-3}$ Nevertheless, it is possible that similar physical benefits might be achieved from group programmes of similar duration that are based upon light exercise rather than high intensity exercise training. A lower level of exercise would largely remove the hazards of cardiac arrest or skeletal injury and avoid the need for medical supervision.

The Austin Hospital Cardiac Rehabilitation
Trial was set up to test the hypothesis that the benefits of aerobic exercise training could be equally well achieved through a less expensive programme of light exercise based upon physiotherapy. The study was an open management trial in which male patients were randomly allocated to eight weeks in a programme of group aerobic exercise training or a programme of group light exercise. This was a consecutive series of patients admitted to a single coronary care unit. Short term and long term physical, psychological, occupational, social, and marital adjustments were investigated. The end point of this study was physical working capacity (as an estimate of maximal total body oxygen uptake) measured by treadmill testing eight weeks and 12 months after entry into the programme.

\section{Patients and methods}

Men aged less than 70 with electrocardiographic evidence of transmural acute myocardial infarction were eligible for the programme. Transmural myocardial infarction was determined according to electrocardiographic criteria of the World Health Organisation (1959), namely, new abnormal $Q$ waves and the development of characteristic ST and T wave changes. ${ }^{4}$ Patients with posterior myocardial infarction, as defined by Perloff, 5 were also eligible. An increase in the activity of cardiac enzymes in the serum to more than twice the upper limit of normal (normal: creatine kinase $<180 \mathrm{IU} / 1$, aspartate transaminase $<30 \mathrm{IU} / \mathrm{l}$ ) was required to confirm that the infarct was recent.

Non-transmural or non- $Q$ wave infarction generally results in a smaller infarct, ${ }^{6}$ a high incidence of subsequent angina, ${ }^{78}$ more frequent reinfarction, ${ }^{7910}$ and more frequent coronary artery bypass graft surgery. ${ }^{910}$ For these reasons, patients with non-transmural acute myocardial infarction were excluded from the study.

Short term and long term coronary prognostic indices were calculated for all patients. ${ }^{1112}$ The electrocardiographic infarct site was determined from the electrocardiogram. ${ }^{13}$ For purposes of analysis, patients with anterior and lateral myocardial infarctions were grouped together, as were those with inferior and posterior myocardial infarctions. Clinical heart 
failure was graded by Killip class. ${ }^{14}$ Gradings of radiographic heart failure and radiographic heart size were assessed by a portable chest radiograph. ${ }^{11} \mathrm{~A}$ medical history of previous ischaemia and previous infarction was noted; as was electrical reversion from ventricular fibrillation.

We used the following exclusion criteria: death or cardiogenic shock in the coronary care unit; physical or psychological disability considered sufficient to impair participation in an exercise programme; residence at considerable distance from programme venues; inadequate command of English; anticipated non-compliance or expressed reluctance to participate; contamination, determined by expressed preference for one or other programme; and other reasons including early transfer to another hospital and administrative error.

At discharge from the coronary care unit, patients were randomly allocated to a programme of exercise training or light exercise rehabilitation. Hospital management of both groups of patients was identical. All patients had the same staff, advice, literature, and baseline evaluations. The randomisation procedure was based on the method of Peto et al by which the random allocation to treatment groups is balanced by even-numbered groups of subjects. ${ }^{15}$ Patients were classified as having pulmonary oedema according to whether they had radiographic and/or clinical evidence of pulmonary oedema in the coronary care unit. Those with pulmonary oedema were randomly allocated as a separate group. Patients entered the trial if they had the entry exercise test and had attended one exercise class. All patients gave their informed consent to enrolment in an exercise programme and to participation in repeated exercise testing and reviews.

We analysed data by the SPSS $x$ package. We used $t$ tests or $\chi^{2}$ tests, with Yates's correction as appropriate, to compare results in the two groups. Probability levels were rounded to three decimal places. For some comparisons of small numbers, we calculated Fisher's exact probability (one sided) to check the $\chi^{2}$ value. All other probabilities quoted are two sided. The expected sample size of this trial (about 150 patients randomised to each programme) provides considerable power ( $95 \%$ ) to detect a difference in mean physical performance as small as 1 MET in a two sided test at the $1 \%$ level of significance.

The exercise training programme complied with the recommendations of the 1979 American Heart Association Committee Report on Standards for Cardiovascular Exercise Treatment Programs. ${ }^{16}$ Every session was attended by an exercise physiologist and physician. Resuscitation equipment was present in the gymnasium (Heidelberg YMCA). Classes were held on three days a week for eight weeks. The first attendance was usually in the second week (8-14 days) after myocardial infarction when patients watched the class. The aerobic training segment started after the first symptom limited exercise test performed in the third week (15-21 days). Exercise classes began with 10 minutes of warm up activities-generally muscle stretching on rubber mats in a gymnastics room. The aerobic segment was based on walking and jogging in the major gymnasium (a basketball court). Exercise levels were prescribed on an individual basis and calculated from the symptom limited exercise test at entry. An additional exercise test was performed in the fourth week to define modification of the training heart rate. Patients performed 30 minutes of continuous aerobic exercise at a level of energy expenditure that maintained their heart rate at $75-85 \%$ of maximum. Pulse rates were checked every five minutes. A 15 minute cooling down phase consisted of more static stretching and light calisthenics. Patients were repeatedly advised of the need to attend sessions to achieve a training effect.

The light exercise programme was conducted in a single hospital room supervised by one or two physiotherapists, with a physician available if required. Most patients first attended in the second week (8-14 days) after myocardial infarction to watch the class. From the third week, patients attended two classes a week for eight weeks. Activities included calisthenics and exercises on a stationary bicycle, a set of steps, weights, and a rowing machine. Exercise was interrupted by periods of rest, thereby reducing a significant training effect. Patients were allowed to increase their pulse rate intermittently to no greater than 20 beats per minute above the resting level. They were advised of the desirability of attending classes until they felt they need no longer attend.

Patients in both groups were also asked to walk each day at a comfortable pace for at least 30 minutes. For those patients in whom pulmonary oedema developed in the coronary care unit, entry into both programmes was postponed for two weeks.

All exercise tests were symptom limited maximal graded treadmill tests performed on a computer controlled Viagraph (IMC, Denver, Colorado, USA) exercise testing system with continuous monitoring and recording each minute of a modified 12 lead electrocardiogram. For balance, patients were allowed lightly to touch the hand rail. ${ }^{1718}$ Blood pressure was recorded every three minutes the conventional way by auscultation in the early stages of testing and each minute towards the end of the test, as required. Tests were stopped if disabling symptoms, hypotension (a drop in systolic blood pressure of more than $20 \mathrm{~mm} \mathrm{Hg}$ compared with an earlier stage), or ventricular tachycardia (the presence of more than three successive ventricular extrasystoles) developed. Medications, including $\beta$ adrenoreceptor blocking agents, were not stopped before exercise testing. Both patient groups had their entry exercise test in the third week after acute myocardial infarction. Exit tests were conducted in the eleventh week when the programmes had been completed. A review treadmill test and physical examination were conducted 12 months after trial entry.

All entry and prescription treadmill tests were performed according to fixed rate protocols. ${ }^{19}$ The exit and 12 month tests were usually 
Distribution of eligible patients showing numbers excluded, randomised, included, or withdrawn at each stage.

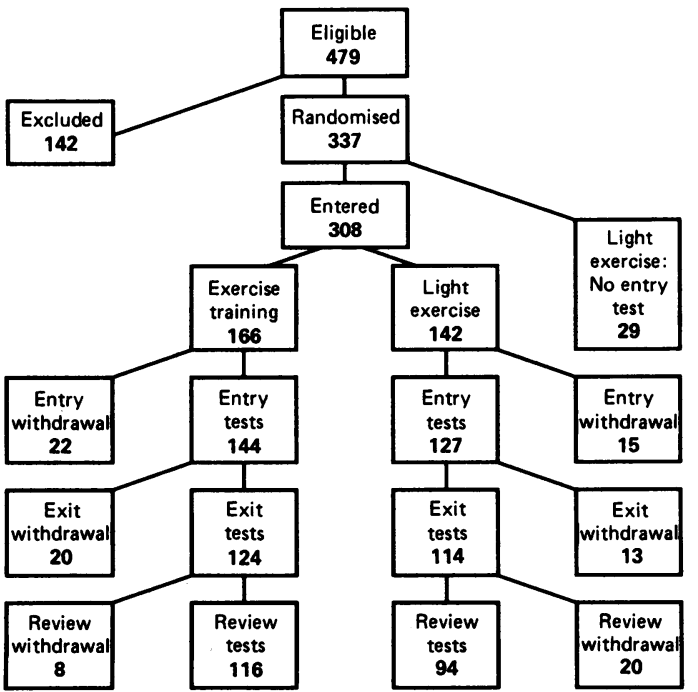

performed according to a Bruce protocol ${ }^{17}$; but under some circumstances, a fixed rate protocol was used. Physical working capacity was estimated from standard nomograms for maximal oxygen uptake and expressed as multiples of resting energy expenditure (METs) where 1 MET = total body oxygen uptake of $3.5 \mathrm{ml}$ $\mathrm{min} /$ per kg body weight. ${ }^{17}$ We used the ratepressure product as an index of myocardial oxygen consumption and defined it as the highest product of simultaneously measured heart rate and systolic blood pressure during the exercise test. ${ }^{20}$

During the eight week rehabilitation programmes, patients received medication to control angina, blood pressure, dyspnoea, or cardiac failure, as required.

Withdrawal from the trial was defined as failure to undergo the prescribed treadmill tests. Withdrawals occurred between randomisation and entry tests (entry withdrawals), between entry and exit tests (exit withdrawals), and between exit and review tests (review withdrawals) because of death, coronary artery

Table 1 Reasons for exclusion of 142 patients with acute myocardial infarction from trial

\begin{tabular}{lr}
\hline Reason & No \\
\hline Death in CCU & 37 \\
Cardiogenic shock & 6 \\
Physical disability & 33 \\
Psychological disability & 3 \\
Distance & 30 \\
Inadequate English & 11 \\
Anticipated non-compliance & 12 \\
Contamination & 5 \\
Other & 5 \\
\hline
\end{tabular}

CCU, coronary care unit.

Table 2 Reasons for withdrawal

\begin{tabular}{|c|c|c|c|c|c|c|}
\hline \multirow[b]{2}{*}{ Reason } & \multicolumn{2}{|l|}{ Entry } & \multicolumn{2}{|l|}{ Exit } & \multicolumn{2}{|l|}{ Review } \\
\hline & $\begin{array}{l}E T \\
(n=22)\end{array}$ & $\begin{array}{l}L E \\
(n=15)\end{array}$ & $\begin{array}{l}E T \\
(n=20)\end{array}$ & $\begin{array}{l}L E \\
(n=13)\end{array}$ & $\begin{array}{l}E T \\
(n=8)\end{array}$ & $\begin{array}{l}L E \\
(n=20)\end{array}$ \\
\hline $\begin{array}{l}\text { Death } \\
\text { Bypass surgery } \\
\text { Other disability } \\
\text { Non-compliance } \\
\text { Distance }\end{array}$ & $\begin{array}{l}8 \\
3 \\
6 \\
3 \\
2\end{array}$ & $\begin{array}{l}6 \\
1 \\
3 \\
4 \\
1\end{array}$ & $\begin{array}{l}5 \\
9 \\
3 \\
3 \\
\end{array}$ & $\begin{array}{l}4 \\
2 \\
2 \\
5 \\
-\end{array}$ & $\begin{array}{l}1 \\
5 \\
1 \\
1 \\
-\end{array}$ & $\begin{array}{l}3 \\
8 \\
3 \\
4 \\
2\end{array}$ \\
\hline
\end{tabular}

Intergroup differences were not significant (Fisher's exact test).

ET, exercise training; LE, light exercise. bypass graft surgery (undertaken only for severe angina not controlled by medication), physical disability preventing exercise testing, or when patient refusal or distance prevented attendance. Patients were encouraged to attend as many classes as possible. Non-attendance at classes, however, did not constitute withdrawal. It was recognised that incomplete attendance was likely for many reasons, including early resumption of work. Class attendances were recorded.

\section{Results}

During the five year enrolment period, 479 men with transmural acute myocardial infarction who satisfied the trial admission criteria were admitted consecutively to the coronary care unit.

One hundred and forty two patients were excluded. The figure shows the distribution of patients excluded, randomised, and withdrawn from the trial. Table 1 shows that death and cardiogenic shock in the coronary care unit were important reasons for exclusion (43 patients) and we noted that excluded patients were older; had higher coronary prognostic indices; a higher incidence of previous infarction; and a greater incidence of clinical cardiac failure, radiographic cardiac failure, and increased radiographic heart size.

Three hundred and thirty seven patients were randomised, 166 to exercise training and 171 to light exercise. Twenty nine consecutive patients randomised to light exercise were allocated to a group that did not have an entry exercise test so that any effect of the entry exercise test could be separately examined. The admission characteristics of these 29 patients, who are not included in the current analysis, were not different from the 142 who remained in the light exercise group. Of the 308 remaining patients, 34 were classified as having pulmonary oedema in the coronary care unit.

Fifty $(30 \%)$ patients in the exercise training group and $48(34 \%)$ in the light exercise group were withdrawn from the study (table 2). Patients who were withdrawn at entry and exit were older (mean age) and had higher coronary prognostic indices, more clinical and radiographic evidence of heart failure, and previous ischaemia and previous infarction than did patients who completed their programmes. No events requiring admission to hospital occurred during treadmill tests or classes in either group.

There were 238 men (236 white) who completed their exercise programmes by attending for an exit treadmill test. One hundred patients $(42 \%)$ held white collar jobs and $138(58 \%)$ had blue collar ones. Fifty eight per cent $(138)$ of the 238 patients were cigarette smokers up to the time of admission to hospital. There were no significant differences in these characteristics between the exercise groups. Table 3 shows the physical entry characteristics of the 238 patients. These characteristics were well matched on all criteria but one: more patients in exercise training had anterior infarction $(p=0.073)$. The admission characteristics of 
Table 3 Admission characteristics of 238 patients who had entry and exit treadmill tests

\begin{tabular}{|c|c|c|}
\hline Variable & $E T(n=124)$ & $L E(n=114)$ \\
\hline $\begin{array}{l}\text { Age (yr) } \\
\text { Weight (kg) } \\
\text { Height }(\mathrm{cm}) \\
\text { Total cholesterol (mmol/l) }\end{array}$ & $\begin{array}{c}52 \cdot 7(8 \cdot 2) \\
80 \cdot 5(10 \cdot 5) \\
174 \cdot 0(6 \cdot 9) \\
6 \cdot 1(1 \cdot 4)\end{array}$ & $\begin{array}{c}52 \cdot 0(8 \cdot 9) \\
79 \cdot 7(11 \cdot 5) \\
174 \cdot 5(6 \cdot 4) \\
6 \cdot 1(1 \cdot 3)\end{array}$ \\
\hline $\begin{array}{l}\text { Coronary prognostic index } \\
\text { Short term (Norris) } \\
\text { Long term (Norris) } \\
\text { Missing }\end{array}$ & $\begin{array}{l}5 \cdot 2(1 \cdot 8) \\
3 \cdot 4(2 \cdot 3) \\
2\end{array}$ & $\begin{array}{l}5 \cdot 2(1 \cdot 9) \\
3 \cdot 5(2 \cdot 4)\end{array}$ \\
\hline $\begin{array}{l}\text { Enzyme activity } \\
\text { CK }(\mathrm{n}<180 \text { IU) } \\
\text { AST }(\mathrm{n}<30 \text { IU })\end{array}$ & $\begin{array}{l}1790(1067) \\
273(151)\end{array}$ & $\begin{array}{l}1958(1139) \\
293(183)\end{array}$ \\
\hline $\begin{array}{c}\text { Infarct site }(\mathbf{n}(\%)) \dagger \\
\text { Anterior/lateral } \\
\text { Inferior/posterior }\end{array}$ & $\begin{array}{l}61(49) \\
63(51)\end{array}$ & $\begin{array}{l}42(37) \\
72(63)\end{array}$ \\
\hline $\begin{array}{l}\text { Failure (Killip class) (n(\%)) } \\
\text { (1) Lungs clear } \\
\text { (2) Basal crepitations } \\
\text { (3) Upper crepitations }\end{array}$ & $\begin{array}{c}74(60) \\
46(37) \\
4(3)\end{array}$ & $\begin{array}{c}75(66) \\
35(31) \\
4(3)\end{array}$ \\
\hline $\begin{array}{l}\text { Failure (radiographic) (n (\%)) } \\
\text { Lungs clear } \\
\text { Venous congestion } \\
\text { Interstitial oedema } \\
\text { Pulmonary oedema } \\
\text { Missing }\end{array}$ & $\begin{array}{l}86(71) \\
27(22) \\
5(4) \\
4(3) \\
2\end{array}$ & $\begin{array}{c}72(63) \\
33(29) \\
5(4) \\
4(4)\end{array}$ \\
\hline $\begin{array}{l}\text { Pulmonary oedema } \\
\text { Clinical and/or radiographic evidence (n (\%)) }\end{array}$ & $9(7)$ & $10(8)$ \\
\hline $\begin{array}{l}\text { Radiographic heart size }(\mathbf{n}(\%)) \\
\text { Normal } \\
\text { Borderline } \\
\text { Enlarged } \\
\quad \text { Missing } \\
\text { Previous ischaemia }(\mathrm{n}(\%)) \\
\text { Previous infarction }(\mathrm{n}(\%)) \\
\text { Electrical reversion }(\mathrm{n}(\%))\end{array}$ & $\begin{array}{l}86(71) \\
31(25) \\
5(4) \\
2 \\
28(23) \\
10(8) \\
12(10)\end{array}$ & $\begin{array}{l}78(68) \\
28(25) \\
8(7) \\
\\
22(19) \\
10(9) \\
7(6)\end{array}$ \\
\hline
\end{tabular}

Results are expressed as mean (SD) and as number of patients (\%).

$\star$ Excludes patients who underwent electrical reversion.

†The intergroup difference in infarct site is not statistically significant $(p=0.073)$.

ET, exercise training; LE, light exercise.

the 210 patients who attended for review exercise tests at 12 months were not significantly different from those of the 238 who had entry and exit exercise tests.

Because exercise training classes were held three times a week (compared with twice a week for light exercise) and more definite encouragement was given to the patients to attend classes, patients attended exercise training more often and over a longer period. Of the exercise training patients, $65 \%$ attended more than three quarters of the total classes possible and $89 \%$ attended more than half. Only $41 \%$ of light exercise patients attended more than three quarters of their classes and $75 \%$ attended more than half $(p<0.001)$. Over $90 \%$ of patients in each group claimed that they complied with advice to walk each day for at least 30 minutes.

Table 4 Medication at time of treadmill tests

\begin{tabular}{|c|c|c|c|c|c|c|}
\hline \multirow[b]{2}{*}{ Treatment } & \multicolumn{2}{|l|}{ Entry } & \multicolumn{2}{|l|}{ Exit } & \multicolumn{2}{|l|}{ Review } \\
\hline & $\begin{array}{l}E T \\
(n=124)\end{array}$ & $\begin{array}{l}L E \\
(n=114)\end{array}$ & $\begin{array}{l}E T \\
(n=124)\end{array}$ & $\begin{array}{l}L E \\
(n=114)\end{array}$ & $\begin{array}{l}E T \\
(n=116)\end{array}$ & $\begin{array}{l}L E \\
(n=94)\end{array}$ \\
\hline $\begin{array}{l}\text { Diuretic } \\
\text { Digoxin } \\
\beta \text { Blocker } \\
\text { Calcium antagonist } \\
\text { Hypotensive } \\
\text { Glyceryl trinitrate } \\
\text { Nitrate } \\
\text { Antiarrhythmic } \\
\text { Psychotropic } \\
\text { Other }\end{array}$ & $\begin{array}{c}30(24) \\
5(4) \\
12(10) \\
17(14) \\
6(5) \\
11(9) \\
3(2) \\
6(5) \\
10(8) \\
30(23)\end{array}$ & $\begin{array}{c}29(25) \\
5(4) \\
12(11) \\
18(16) \\
4(4) \\
12(11) \\
5(4) \\
8(7) \\
10(9) \\
18(16)\end{array}$ & $\begin{array}{c}28(23) \\
3(2) \\
22(18) \\
14(11) \\
6(5) \\
7(6) \\
1(1) \\
5(4) \\
11(9) \\
30(23)\end{array}$ & $\begin{array}{c}28(25) \\
5(4) \\
22(19) \\
22(19) \\
5(4) \\
10(9) \\
2(2) \\
6(5) \\
5(4) \\
26(23)\end{array}$ & $\begin{array}{c}28(24) \\
3(3) \\
23(20) \\
14(12) \\
7(6) \\
10(9) \\
2(2) \\
2(2) \\
13(11) \\
30(26)\end{array}$ & $\begin{array}{c}23(24) \\
7(7) \\
23(24) \\
14(15) \\
4(4) \\
4(4) \\
1(1) \\
1(1) \\
8(8) \\
19(20)\end{array}$ \\
\hline
\end{tabular}

Results are expressed as number of patients (\%).

$\star$ There was a similar and significant $(p<0.014)$ increase in total $\beta$ blocker treatment between entry and exit in both groups $(24 v 44)$. There were no significant intergroup differences in any type of medication at entry, exit, or review.

ET, exercise training; LE, light exercise.
At the time of each exercise test there were no intergroup differences for any form of medication (table 4). At each stage similar proportions of patients were taking $\beta$ adrenoreceptor blocking medication. The only significant change in medication between entry and exit tests in both groups was an increase in the use of $\beta$ adrenoreceptor blocking drugs ( 24 patients at entry test and 44 patients at exit test $(p=0.014))$.

The distributions of treadmill test protocols were similar in both study groups (table 5). At entry most patients had fixed rate protocols with increments of $4 \%$ in the incline from horizontal every three minutes at a speed of $3.2 \mathrm{~km}$ per hour or $4.8 \mathrm{~km}$ per hour. A few patients who showed and claimed rapid recovery and considerable fitness had their entry test at $5.6 \mathrm{~km}$ per hour. The Bruce protocol was mainly used at exit $(83 \%)$ and 12 month review (92\%), but some patients who were unfit or who had difficulty in handling a simultaneous increase of speed and incline had a fixed rate protocol test.

Table 6 sets out the treadmill test results. At entry, exit, or 12 month review tests there were no significant intergroup differences in mean resting heart rate, resting systolic blood pressure, maximal heart rate, maximal systolic blood pressure, or rate pressure product. Further, there were no significant differences between groups in the reasons for stopping treadmill tests, nor were there differences between groups at any test in the distribution of the degree of ST segment depression. While physical working capacity during the entry test was not significantly different between groups, at the exit test there was a significant mean difference of $0.9 \mathrm{MET}$ between the groups $(p=0.002)$. At the 12 month review, there was no significant intergroup difference in physical working capacity.

Between the entry and exit tests the physical working capacity (METs (SD)) increased significantly more with exercise training $(4 \cdot 0(1 \cdot 9))$ than with light exercise $(3 \cdot 1(2 \cdot 0))(\mathrm{p}<0.001)$. Between the exit test and review test the physical working capacity in the 94 patients in light exercise was $0.6(1 \cdot 7)$ METs compared with $-0.1(1.6)$ METs in the 116 patients in exercise training ( $p=0.007$ )

We performed subset analyses to assess whether different distributions of the infarct site influenced the observed difference in physical working capacity between the exercise training group and light exercise group during the exit test (table 7). For both sites, the physical working capacity for the entry test was similar for patients in each programme. The exit test performances of both exercise training subsets were higher than those of the light exercise subsets with similar infarction sites. Patients who had pulmonary oedema followed the same trends as did those without (table 7).

\section{Discussion}

We compared the physical benefits of two programmes of different levels of exercise. The study was not designed to answer the question whether rehabilitation programmes based 
Table 5 Treadmill test protocols

\begin{tabular}{|c|c|c|c|c|c|c|}
\hline \multirow[b]{2}{*}{ Protocol } & \multicolumn{2}{|l|}{ Entry } & \multicolumn{2}{|l|}{ Exit } & \multicolumn{2}{|l|}{ Review } \\
\hline & $\begin{array}{l}E T \\
(n=124)\end{array}$ & $\begin{array}{l}L E \\
(n=114)\end{array}$ & $\begin{array}{l}E T \\
(n=124)\end{array}$ & $\begin{array}{l}L E \\
(n=114)\end{array}$ & $\begin{array}{l}E T \\
(n=116)\end{array}$ & $\begin{array}{l}L E \\
(n=94)\end{array}$ \\
\hline $\begin{array}{l}\text { Fixed rate } \\
3.2 \mathrm{~km} / \mathrm{h}(2.0 \mathrm{mph}) \\
4.8 \mathrm{~km} / \mathrm{h}(3.0 \mathrm{mph}) \\
5.2 \mathrm{~km} / \mathrm{h}(3.5 \mathrm{mph}) \\
\text { Bruce }\end{array}$ & $\begin{array}{c}65(53) \\
56(45) \\
3(2) \\
-\end{array}$ & $\begin{array}{c}61(53) \\
52(46) \\
1(1) \\
-\end{array}$ & $\begin{array}{c}3(2) \\
10(8) \\
6(5) \\
105(85)\end{array}$ & $\begin{array}{c}2(2) \\
14(12) \\
6(5) \\
92(81)\end{array}$ & $\begin{array}{c}3(3) \\
3(3) \\
1(1) \\
109(94)\end{array}$ & $\begin{array}{c}1(1) \\
6(6) \\
3(2) \\
84(89)\end{array}$ \\
\hline
\end{tabular}

^Fixed rate protocols with stages of three minutes and a $4 \%$ increase in incline at each stage. Results are expressed as number of patients (\%).

There were no significant differences in the distribution of treadmill protocols at any stage. ET, exercise training; LE, light exercise.

upon group exercise are more effective than usual medical care and an individual programme of exercise and walking at home.

The main finding of the study was that though physical working capacity, assessed by treadmill performance, increased more in the exercise training group than in the light exercise group, the difference was small and only temporary. The difference was not accompanied by a significant mean intergroup difference in rate-pressure product.

The results of our study are likely to apply widely. The Austin Hospital serves both as a community hospital and as a major university teaching hospital. The pattern of patient admissions to the coronary care unit, either directly or through the emergency department, is similar to that in most major hospitals in Australia and elsewhere. Exclusions were only for defined physical, psychological, or geographical reasons. Death was the commonest reason for both exclusion and withdrawal; mortality ( $13 \%$ by one year) was similar to that reported in other investigations. ${ }^{21}{ }^{22}$ The number of randomised patients withdrawn at each stage was small. Death $(9 \%$ and coronary artery bypass graft surgery $(9 \%)$ were the main reasons for these withdrawals.

The two exercise protocols tested in this trial are representative of the protocols followed elsewhere. The exercise training programme was based on the recommendations of the 1979 American Heart Association report ${ }^{16}$ while the light exercise programme conformed to common exercise based rehabilitation programmes offered to cardiac patients in Australian hospitals.

The end point in this study, physical working capacity, was determined by performance on a treadmill. Nomograms for maximal oxygen uptake are regarded as appropriate measures for both individual and group studies, ${ }^{17}{ }^{19}$ though some limitations have been suggested. ${ }^{23}$ Maximal oxygen uptake correlates well with performance on a treadmill but the standard equations tend to overpredict performance. ${ }^{24}$ Routine direct measurement of maximal oxygen uptake in large numbers of patients is impractical and the patient's performance on a treadmill (expressed in METs) is generally regarded as an appropriate measure of physical working capacity. Maximal oxygen uptake and performance on the treadmill were similar for fixed rate and Bruce exercise protocols. ${ }^{2325}$

Groups were well matched except for the site of infarction. This, however, did not distort the overall results of the trial. The other possible source of bias, the withdrawal of patients for coronary bypass surgery, did not significantly affect the results either.

In the exercise training group, the mean increment in physical working capacity achieved after eight weeks was similar to the outcome of gymnasium training in the study of DeBusk et al, and this result was consistent with the similarities between our exercise training and their gymnasium training programmes. $^{3}$ The increment in mean physical working capacity after eight weeks in our light exercise group was greater than the spontaneous improvement during a similar period. ${ }^{326}$ It was similar to the improvement reported by DeBusk et al by a home exercise training programme ${ }^{3}$ but greater than that achieved by both home and group training in their subsequent study. ${ }^{26}$ Though our light exercise programme was designed to reassure patients about the safety of activity during convalescence rather than to achieve a training effect, and though most of the patients in this group attended fewer classes than those in the exercise training group, the programme of light exercise contributed to an increase in physical working capacity. Compliance with advice and encouragement to walk and exercise daily, with twice weekly group support in this aim, was likely to have led to progressive training of those muscle groups used during the tests on the treadmill.

In a smaller study, Blumenthal et al found no significant increase in maximal oxygen consumption during treadmill testing between groups enrolled in exercise training pro-

Table 6 Treadmill test results (mean $(S D)$ )

\begin{tabular}{|c|c|c|c|c|c|c|}
\hline \multirow[b]{2}{*}{ Variable } & \multicolumn{2}{|l|}{ Entry } & \multicolumn{2}{|l|}{ Exit } & \multicolumn{2}{|l|}{ Review } \\
\hline & $\begin{array}{l}E T \\
(n=124)\end{array}$ & $\begin{array}{l}L E \\
(n=114)\end{array}$ & $\begin{array}{l}E T \\
(n=124)\end{array}$ & $\begin{array}{l}L E \\
(n=114)\end{array}$ & $\begin{array}{l}E T \\
(n=116)\end{array}$ & $\begin{array}{l}L E \\
(n=94)\end{array}$ \\
\hline $\begin{array}{l}\text { HR } \\
\text { SBP (mm Hg) } \\
\text { HR max } \\
\text { SBP max }(\mathrm{mm} \mathrm{Hg}) \\
\text { RPP } \times 10^{-2} \\
\text { PWC (METs) }\end{array}$ & $\begin{array}{c}83.9(14.2) \\
116.5(18.0) \\
147.7(19.5) \\
153.3(25.1) \\
223.5(52.5) \\
6.8(2 \cdot 2)\end{array}$ & $\begin{array}{c}84.3(13.8) \\
117.7(15.2) \\
145.8(21.4) \\
151.5(28.8) \\
220.0(57.5) \\
6.7(2.5)\end{array}$ & $\begin{array}{r}81 \cdot 0(14 \cdot 7) \\
121 \cdot 2(16 \cdot 1) \\
156.6(20.6) \\
161.7(27.0) \\
250.4(57.9) \\
10.8(2 \cdot 3)^{\star}\end{array}$ & $\begin{array}{r}82.3(13.5) \\
121.1(18.0) \\
153.3(20.7) \\
159.7(27.8) \\
242.8(58.8) \\
9.9(2.4)^{\star}\end{array}$ & $\begin{array}{c}78 \cdot 1(12.4) \\
130.4(18.5) \\
157.6(22 \cdot 1) \\
167.5(26.6) \\
263.0(61.6) \\
10.8(2 \cdot 4)\end{array}$ & $\begin{array}{r}77 \cdot 1(15 \cdot 0) \\
126.9(18 \cdot 3) \\
154.9(22 \cdot 9) \\
167 \cdot 3(26 \cdot 7) \\
255 \cdot 2(58 \cdot 8) \\
10.7(1.9)\end{array}$ \\
\hline
\end{tabular}

$\star P W C$ at exit test is the only significant intergroup difference $p=0.002$ )

ET, exercise training; LE, light exercise. HR, resting heart rate standing (beats per minute); HR max, maximal heart rate during test (beats per minute); PWC, phax stolic blood pressure during test. 
Table 7 Physical working capacity (METs (SD)) at entry and exit tests according to infarct site and pulmonary oedema at admission

\begin{tabular}{|c|c|c|c|}
\hline Infarct size & $E T$ & $L E$ & $p$ \\
\hline $\begin{array}{l}\text { Anterior } \\
\text { Entry } \\
\text { Exit } \\
\text { Increment }\end{array}$ & $\begin{array}{c}(\mathrm{n}=61) \\
6 \cdot 4(2 \cdot 1) \\
10 \cdot 8(2 \cdot 3) \\
4 \cdot 4(2 \cdot 0)\end{array}$ & $\begin{array}{l}(\mathrm{n}=42) \\
6 \cdot 4(2 \cdot 6) \\
9 \cdot 5(2 \cdot 4) \\
3 \cdot 1(2 \cdot 0)\end{array}$ & $\begin{array}{l}\text { NS } \\
0.008 \\
0.003\end{array}$ \\
\hline $\begin{array}{l}\text { Inferior } \\
\text { Entry } \\
\text { Exit } \\
\text { Increment }\end{array}$ & $\begin{array}{c}(n=63) \\
7 \cdot 1(2 \cdot 3) \\
10 \cdot 8(2 \cdot 4) \\
3 \cdot 7(1 \cdot 6)\end{array}$ & $\begin{array}{c}(\mathrm{n}=72) \\
6.9(2.4) \\
10.0(2.4) \\
3.1(1.9)\end{array}$ & $\begin{array}{l}\text { NS } \\
0.07 \\
0.06\end{array}$ \\
\hline $\begin{array}{l}\text { Pulmonary oedema } \\
\text { Entry } \\
\text { Exit } \\
\text { Increment }\end{array}$ & $\begin{array}{l}(\mathbf{n}=9) \\
5 \cdot 7(2 \cdot 2) \\
9 \cdot 9(2 \cdot 9) \\
4 \cdot 2(1 \cdot 4)\end{array}$ & $\begin{array}{l}(\mathrm{n}=10) \\
5.0(1.3) \\
8.3(1.9) \\
3.4(1.9)\end{array}$ & $\begin{array}{l}\text { NS } \\
\text { NS } \\
\text { NS }\end{array}$ \\
\hline
\end{tabular}

ET, exercise training; LE, light exercise.

grammes of high or low intensity. ${ }^{27}$ Their patients were also active, walking daily, as well as attending their exercise sessions.

Our study shows that, in the first weeks after myocardial infarction, there is a significant slowing of resting heart rate and a rise in systolic blood pressure towards preinfarction values. The achievable maximal heart rate and maximal systolic blood pressure also increase. In consequence, rate-pressure product increases significantly during the initial weeks after myocardial infarction. This increase was no larger in the exercise training group than in the light exercise group.

It seems that differences in maximal oxygen uptake caused by aerobic exercise training arise largely from an effect on peripheral muscle groups used for walking, rather than from a central cardiopulmonary effect. This conclusion is supported by other studies. ${ }^{28-30}$ Indeed, it would be unreasonable to expect a central cardiac or respiratory training effect from an eight week programme of three sessions per week in middle aged or elderly individuals.

Mobilisation and resumption of normal activities after a period of bed rest are known to be associated with rapid recovery of functional capacity. ${ }^{31}$ We showed that a low cost, low intensity group exercise programme was almost as effective in the short term and was as effective at one year as aerobic exercise training for the rehabilitation of patients after acute myocardial infarction.

We thank the National Heart Foundation of Australia for support.

1 Wilhelmsen L, Sanne H, Elmfeldt D, Grimby G, Tibblin G Wedel H. A controlled trial of physical training after myocardial infarction. Prev Med 1975;4:491-508.

2 Rechnitzer PA, Sangal S, Cunningham DA, et al. A controlled prospective study of the effect of endurance training on the recurrence rate of myocardial infarction. Am J Epidemiol 1975;102:358-65.

3 DeBusk RF, Houston N, Haskell W, Fry G, Parker M. Exercise training soon af

4 First Report of the Expert Committee on Cardiovascular Diseases and Hypertension. WHO Tech Rep Ser 1959:168.
5 Perloff JK. The recognition of strictly posterior myocardial infarction by conventional scalar electrocardiography. Circulation 1964;30:706-18.

6 Geltman EM, Biello D, Welch MJ, Ter-Pogossian MM, Roberts R, Sobel BE. Characterisation of nontransmural myocardial infarction by positronemission tomography. Circulation 1982;65:747-55.

7 Madigan NP, Rutherford BD, Frye RL. The clinical course, early prognosis and coronary anatomy of subendocardia infarction. Am J Med 1976;60:634-41.

8 Cannom DS, Levy W, Cohen LS. The short- and long-term prognosis of patients with transmural and nontransmural myocardial infarction. Am J Med 1976;61:452-8.

9 Hutter AM, DeSanctis RW, Flynn T, Yeatman LA. Nontransmural myocardial infarction: a comparison of hospital and late clinical course of patients with that of matched patients with transmural anterior and transmural inferior myocardial infarction. Am J Cardiol 1981;48:595-602.

10 Gibson RS, Beller GA, Gheorghiade M, et al. The prevalence and clinical significance of residual myocardial ischemia 2 weeks after uncomplicated non- $Q$ wave infarction: a prospective natural history study. Circulation tion: a prospecti

11 Norris RM, Brandt PWT, Caughey DE, Lee AJ, Scott PJ. A new coronary prognostic index. Lancet 1969;i:274-81.

12 Norris RM, Caughey DE, Deeming LW, Mercer CJ, Scot PJ. Coronary prognostic index for predicting survival after recovery from acute myocardial infarction. Lancet 1970;ii:485-8.

13 Prineas RJ, Crow RS, Blackburn H. The Minnesota Code manual of electrocardiographic findings. Boston: John Wright-PSG, 1982.

14 Wolk MJ, Scheidt S, Killip T. Heart failure complicating acute myocardial infarction. Circulation 1972;45:1125-38.

15 Peto R, Pike MC, Armitage P, et al. Design and analysis of randomised clinical trials requiring prolonged observation of each patient. I. Introduction and design. $\mathrm{BrJ}$ Cancer 1976;34:585-612.

16 American Heart Association Subcommittee on Rehabilitation. Standards for cardiovascular exercise treatment programs. Circulation 1979;59:1084A-90A.

17 Bruce RA, Kusumi F, Hosmer D. Maximal oxygen intake and nomographic assessment of functional aerobic impairment in cardiovascular disease. Am Heart $J$ 1973;85: $546-62$.

18 Haskell WL, Savin W, Oldridge N, DeBusk R. Factors influencing estimated oxygen uptake during exercise testing soon after myocardial infarction. $\mathrm{Am} \mathrm{J} \mathrm{Cardiol}$ 1982;50:299-304

19 Balke B, Ware RW. An experimental study of "physical fitness" of Air Force personnel. US Armed Forces Med J 1959;10:675-88.

20 Gobel FL, Nordstrom LA, Nelson RR, Jorgensen CR, Wang $Y$. The rate-pressure product as an index of myocardial oxygen consumption during exercise in patients with angina pectoris. Circulation 1978;57:549-56.

21 Martin CA, Thompson PL, Armstrong BK, Hobbs MST de Klerk $\mathrm{N}$. Long-term prognosis after recovery from de Klerk N. Long-term prognosis after recovery from myocardial infarction: a nine year follow-up of

22 Stone PH, Raabe DS, Jaffe AS. et al. Prognostic significance of location and type of myocardial infarction: independent adverse outcome associated with anterior location. $J A m$ Coll Cardiol 1988;2:453-63.

23 Froehlicher VF, Brammell H, Davis G, Noguera I, Stewart A, Lancaster MC. A comparison of the reproducibility and physiological response to three maximal treadmil exercise protocols. Chest 1974;65:512-7.

24 Foster C, Hare J, Taylor MM, Goldstein T, Anholm JD, Pollock ML. Prediction of oxygen uptake during exercise testing in cardiac patients and

25 Pollock ML Bohannon RL Cooper $\mathrm{KH}$, et al. A comparative analysis of four protocols for maximal treadmill parative analysis of four protocols for maxin
stress testing. Am Heart $J$ 1976;92:39-46.

26 DeBusk RF, Haskell WL, Miller NH, Berra K, Taylor CB Medically directed at-home rehabilitation soon after Medically directed at-home rehabilitation soon after
clinically uncomplicated acute myocardial infarction: a new model for patient care. Am J Cardiol 1985;55:251-7.

27 Blumenthal JA, Rejeski J, Walsh-Riddle M, et al. Comparison of high-and low-intensity exercise training early after acute myocardial infarction. Am J Cardiol 1988;61:26-30.

28 Detry JR, Rousseau M, Vandenbroucke G, Kusami F, Brasseur LA, Bruce RA. Increased arteriovenous oxygen difference after physical training in coronary heart disease. Circulation 1971;44:109-18.

29 Clausen JP, Trap-Jensen J. Effects of training on the distribution of cardiac output in patients with coronary artery disease. Circulation 1970;42:611-24.

30 Sullivan MJ, Higginbotham MB, Cobb FR. Exercise training in patients with severe left ventricular dysfunction: ing in patients with setabolic effects. Circulation 1988;78:506-15.

31 DeBusk RF, Convertino VA, Hung J, Goldwater D. Exercise conditioning in middle-aged men after 10 days of bed rest. Circulation 1983;68:245-50. 